\title{
Treatment of neovascular age-related macular degeneration with anti-VEGF agents: retrospective analysis of 5-year outcomes
}

This article was published in the following Dove Press journal:

Clinical Ophthalmology

29 March 2016

Number of times this article has been viewed

\author{
Ana Catarina Pedrosa \\ Adriana Reis-Silva ${ }^{2}$ \\ João Pinheiro-Costa ${ }^{1,3}$ \\ João Beato' \\ Paulo Freitas-da-Costa ${ }^{1,3}$ \\ Manuel S Falcão ${ }^{1,2}$ \\ Fernando Falcão-Reis ${ }^{1,2}$ \\ Ângela Carneiro ${ }^{1,2}$ \\ 'Department of Ophthalmology, \\ Hospital de São João, ${ }^{2}$ Department \\ of Sense Organs, ${ }^{3}$ Department \\ of Anatomy, Faculty of Medicine, \\ University of Porto, Porto, Portugal
}

Correspondence: Ana Catarina Pedrosa Department of Ophthalmology, Hospital de São João, Alameda Professor Hernâni Monteiro, Porto 4200-319, Portugal Fax +35I 225025766 Email catarina.c.pedrosa@gmail.com
Purpose: To evaluate the 5-year results obtained in clinical practice in the treatment of neovascular age-related macular degeneration (nAMD) with anti-VEGF agents.

Materials and methods: We retrospectively analyzed all patients with nAMD who initiated anti-VEGF treatment before October 2009. We collected data regarding visual and anatomical outcomes.

Results: A total of 278 patients met the selection criteria. The mean number of intravitreal injections was 5.7 in the first year and 3.7 in the fifth year. A positive mean visual acuity variation of +3.7 Early Treatment Diabetic Retinopathy Study letters occurred in the first year, but no significant differences relative to baseline were observed thereafter. The majority of patients $(71 \%)$ maintained stable visual acuity throughout follow-up. At 5 years, mean central macular thickness remained substantially inferior to baseline $(-96.6 \mu \mathrm{m})$, and $56 \%$ of patients maintained dry retinas.

Conclusion: Anti-VEGF therapy leads to long-term visual stabilization in the great majority of patients.

Keywords: age-related macular degeneration, choroidal neovascularization, vascular endothelial growth factor, visual acuity

\section{Introduction}

The treatment of neovascular age-related macular degeneration (nAMD) was revolutionized by the introduction of anti-VEGF agents. In 2006, the pivotal clinical trials $\mathrm{ANCHOR}^{1,2}$ and $\mathrm{MARINA}^{3}$ reported that the natural history of rapid and progressive vision loss characteristic of nAMD could be arrested by monthly injections of ranibizumab. In fact, after 2 years of treatment with ranibizumab, approximately $90 \%$ of patients avoided moderate vision loss (defined as loss of $\geq 15$ Early Treatment Diabetic Retinopathy Study [ETDRS] letters), a considerable proportion gained $\geq 15$ letters (41\% and 33\% in ANCHOR and MARINA, respectively), and mean visual acuity (VA) variation was positive $(+10.7$ and +6.6 letters in ANCHOR and MARINA, respectively).

However, monthly injections of ranibizumab pose a substantial burden on the health care system and on patients, and thus alternative treatment options have been evaluated, such as the use of the off-label and more affordable anti-VEGF agent bevacizumab, and the development of other treatment regimens, including pro re nata (PRN) and "treat and extend". ${ }^{4-6}$ In 2011, the CATT study compared bevacizumab with ranibizumab and monthly injections with PRN treatment. ${ }^{7,8}$ Visual outcomes were equivalent for bevacizumab and ranibizumab when the same treatment modality 
was compared at 1 and 2 years of follow-up. Additionally, no significant differences were apparent between monthly and PRN treatment regimens at the end of the first year, but monthly treatment proved to be superior at the end of the second year.

Randomized clinical trials provide valuable information, but as clinical experience with anti-VEGF agents in nAMD grows, it is essential to evaluate the long-term results in clinical practice. We retrospectively analyzed the 5-year results of nAMD treatment with anti-VEGF agents at a single tertiary center in Portugal.

\section{Materials and methods}

We conducted a retrospective study in the Department of Ophthalmology of Hospital de São João, Porto, Portugal. Study approval was obtained from the ethics committee of Hospital de São João. Written informed consent had previously been obtained from each patient.

The study population included patients with nAMD who initiated treatment with anti-VEGF agents at our center before October 2009 and who were followed up for at least 1 year. Diagnosis of nAMD was established on the basis of fundoscopic examination, optical coherence tomography (OCT), and fluorescein angiography. Anti-VEGF therapy could include bevacizumab, ranibizumab, and/or aflibercept. For patients with two eyes meeting the selection criteria, either the eye with the longer follow-up period or the right eye (if the follow-up period of both eyes was similar) was selected.

Patients who presented at diagnosis best-corrected VA $<10$ ETDRS letters (Snellen equivalent 20/600) or who were considered by the clinician unlikely to benefit from anti-VEGF treatment due to advanced lesions with large areas of subfoveal fibrosis or atrophy were excluded, even if a trial of anti-VEGF treatment was undertaken. On the other hand, patients who received verteporfin photodynamic therapy (PDT) prior to anti-VEGF treatment, and those who were submitted to cataract surgery during follow-up were not excluded.

Patient charts were reviewed to collect all relevant information regarding a 5-year follow-up period, including the baseline visit (which preceded the first anti-VEGF injection), the visits following the first, second, and third injections, and the visits performed approximately 6 months and 1, 2, 3, 4 , and 5 years after the beginning of anti-VEGF therapy. Collected data included: best-corrected VA measured with ETDRS charts; OCT parameters, such as presence of intraretinal (IRF) or subretinal fluid (SRF) and central macular thickness (CMT); and number of injections received and the anti-VEGF agent(s) injected.
At our center, treatment of nAMD with anti-VEGF agents started in December 2006 with the off-label use of bevacizumab. Later, in July 2008, ranibizumab became commercially available and replaced bevacizumab. However, in May 2011, after the CATT study demonstrated that bevacizumab and ranibizumab had equivalent effects on VA when administered according to the same treatment regimen, ${ }^{7}$ bevacizumab became the drug of choice due to a board decision, and ranibizumab was available only for patients who did not respond to bevacizumab. Finally, in May 2013, aflibercept replaced ranibizumab as rescue therapy in patients not responding to bevacizumab.

In 2006, all patients were treated using a PRN regimen with monthly monitoring. Criteria for retreatment included exudation or blood in the macula on fundoscopic examination, IRF or SRF on OCT, and active leakage on fluorescein angiography. However, this strategy proved to be cumbersome and demanding in terms of time and human resources. As the cohort of patients with nAMD under antiVEGF treatment increased, it became impossible to observe all patients monthly, which motivated the development of new strategies. At variable time points, some patients were changed to a regimen similar to "treat and extend", as the attending ophthalmologist tried to identify temporal patterns of neovascular activity for each patient. In cases in which a regular pattern was observed, two or three consecutive injections with a fixed interval without intervening visits were proposed. However, during that visit-free time, patients had easy and rapid access to the treating ophthalmologist if they developed any symptoms.

At our center, assessment and treatment are performed on different days, and treatment takes place in the operating room, under topical anesthesia. The dose of anti-VEGF agents administered is $0.5 \mathrm{mg} / 50 \mu \mathrm{L}$ for ranibizumab, $1.25 \mathrm{mg} / 50 \mu \mathrm{L}$ for bevacizumab, and $2.0 \mathrm{mg} / 50 \mu \mathrm{L}$ for aflibercept.

OCT scans were obtained using the Stratus device (Carl Zeiss Meditec AG, Jena, Germany) until 2009, but more recently they have been obtained using the Spectralis HRA + OCT device (Heidelberg Engineering GmbH, Heidelberg, Germany). In this study, CMT was measured manually using the calipers provided by the software considering as retinal boundaries the inner limiting membrane and the retinal pigment epithelium.

VA change throughout follow-up was classified into three categories: improved (gain $\geq 15$ ETDRS letters), stable (variation $<15$ letters), and decreased VA (loss $\geq 15$ letters). In order to analyze the influence of baseline VA on VA change over time and final absolute VA, baseline VA was 
stratified into five groups: group 1, $\geq 70$; group 2, 55-69; group 3, 40-54; group 4, 25-39; and group 5, <25 ETDRS letters.

Statistical analysis was performed using IBM SPSS Statistics for Windows version 20.0 (IBM Corporation, Armonk, NY, USA), and results were considered statistically significant if $P<0.05$. Continuous variables were compared using the $t$-test for paired or independent samples. Levene's test was performed to assess the homogeneity of the variance when appropriate.

\section{Results}

The selection criteria were met in 278 patients, $59 \%$ of whom were women (Table 1). Age at diagnosis was on average 77 years and varied between 51 and 92 years. Fifteen percent of patients were lost to follow-up at the end of the second year, and this proportion increased to $24 \%, 29 \%$, and $36 \%$ at the third, fourth, and fifth years, respectively. Eighteen percent of the study group had been previously treated with PDT, and cataract surgery was performed during follow-up on $11 \%$ of included patients. The mean number of intravitreal injections was 5.7 during the first year, and decreased to 4.0 in the second year, to 3.8 in the third year, and to 3.7 in the fourth and fifth years (Table 2).

In response to treatment, mean VA increased from a baseline value of 44.2 letters to a peak value of 49.3 letters $(+5.1$-letter variation, $P<0.001)$ after the third injection (Table 2 and Figure 1). Afterward, throughout the 5 years of follow-up, we observed a gradual return to baseline: mean VA was maintained significantly higher than baseline at the

Table I Baseline characteristics of the study group

\begin{tabular}{|c|c|}
\hline Number of patients & 278 \\
\hline Age at diagnosis, years (mean $\pm S D$ ) & $76.78 \pm 7.52$ \\
\hline Age at diagnosis, years (range) & $51-92$ \\
\hline Women, n (\%) & $163(58.6)$ \\
\hline VA, ETDRS letters (mean \pm SD) & $44.15 \pm 18.97$ \\
\hline$V A \geq 20 / 40, n(\%)$ & $23(8.3)$ \\
\hline Previous PDT, n (\%) & $51(18.3)$ \\
\hline Cataract surgery in the study eye & $31(11.2)$ \\
\hline \multicolumn{2}{|l|}{ during follow-up, n (\%) } \\
\hline \multicolumn{2}{|l|}{ CNV lesion subtype, $n(\%)$} \\
\hline Occult & $12 \mid(43.5)$ \\
\hline Minimally classic & $84(30.2)$ \\
\hline Predominantly classic & $45(16.2)$ \\
\hline Retinal angiomatous proliferation & $20(7.2)$ \\
\hline Polypoidal choroidal vasculopathy & $4(1.4)$ \\
\hline Unknown & $4(1.4)$ \\
\hline $\mathrm{CMT}, \mu \mathrm{m}($ mean $\pm \mathrm{SD})$ & $297.36 \pm 154.99$ \\
\hline
\end{tabular}

Abbreviations: SD, standard deviation; VA, visual acuity; ETDRS, Early Treatment Diabetic Retinopathy Study; PDT, photodynamic therapy; CNV, choroidal neovascularization; CMT, central macular thickness.

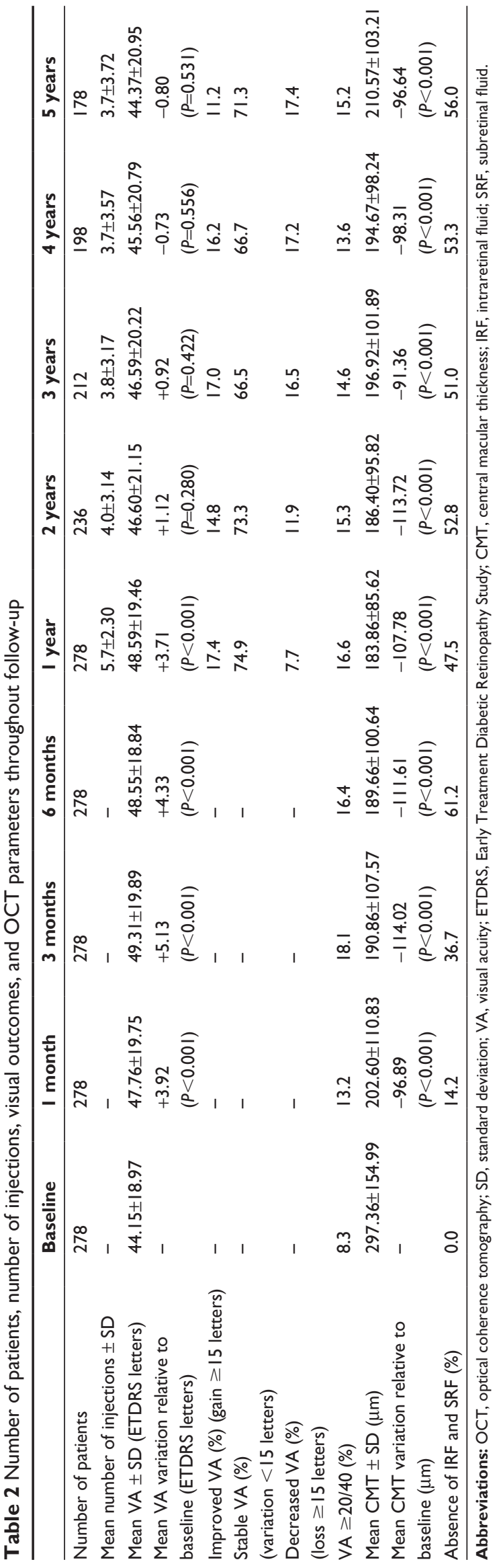




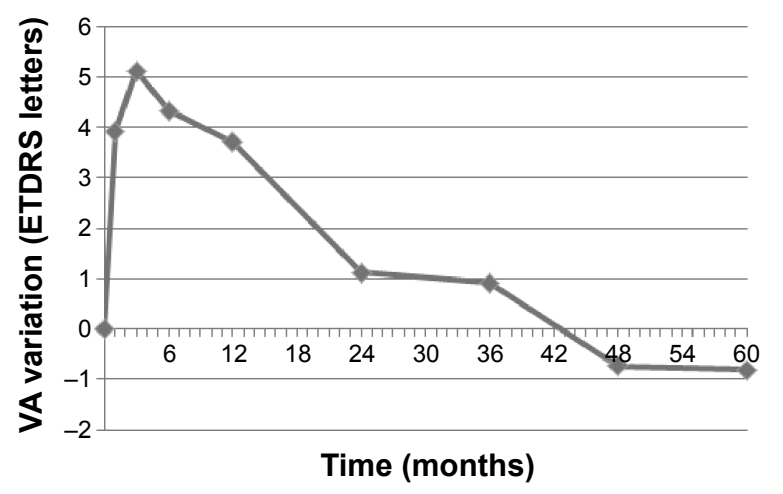

Figure I Mean VA variation throughout follow-up.

Abbreviations: VA, visual acuity; ETDRS, Early Treatment Diabetic Retinopathy Study.

end of the first year $(+3.7$ letters, $P<0.001)$, but no significant differences were registered thereafter (year 2, $+1.1, P=0.280$; year 3, $+0.9, P=0.422$; year $4,-0.7, P=0.556$; year $5,-0.8$, $P=0.531)$. The majority of patients $(71 \%)$ maintained stable VA throughout follow-up. However, $17 \%$ gained 15 or more letters at the end of the first year, a proportion that decreased to $11 \%$ by 5 years. On the other hand, despite treatment, $8 \%$ lost at least 15 letters at the end of the first year, and this proportion increased to $17 \%$ by 5 years.

Only $8 \%$ of patients presented with VA of 20/40 or higher (Table 2). With treatment, this proportion increased to a peak value of $18 \%$ after the third injection and then decreased slightly to $15 \%$ at the end of follow-up.

As depicted in Figure 2 and Table 3, baseline VA influenced VA variation in response to treatment and absolute

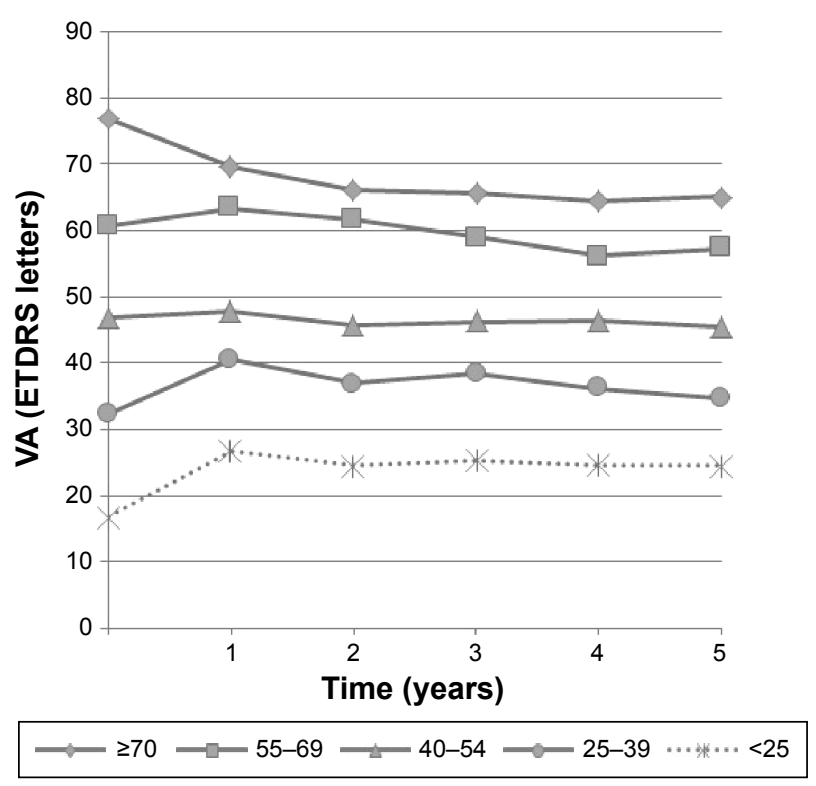

Figure 2 Mean VA throughout follow-up, according to baseline VA ( $\geq 70,55-69$, 40-54, 25-39, and <25 ETDRS letters).

Abbreviations: VA, visual acuity; ETDRS, Early Treatment Diabetic Retinopathy Study.
Table 3 Visual outcomes at 5 years according to baseline VA

\begin{tabular}{lll}
\hline $\begin{array}{l}\text { Baseline VA } \\
\text { (ETDRS letters) }\end{array}$ & $\begin{array}{l}\text { Mean VA at } 5 \text { years } \\
\text { (ETDRS letters) }\end{array}$ & $\begin{array}{l}\text { Mean VA variation } \\
\text { relative to baseline at } \\
\mathbf{5} \text { years (ETDRS letters) }\end{array}$ \\
\hline$\geq 70$ & 65.1 & -12.2 \\
$55-69$ & 57.2 & -3.4 \\
$40-54$ & 45.5 & -1.7 \\
$25-39$ & 34.8 & +2.7 \\
$<25$ & 24.5 & +8.1 \\
\hline
\end{tabular}

Abbreviations: VA, visual acuity; ETDRS, Early Treatment Diabetic Retinopathy Study.

final VA. Patients with higher baseline VA gained fewer letters or lost more letters than those with lower baseline VA, but they maintained a higher absolute VA at the end of follow-up. For example, with regard to patients with baseline $\mathrm{VA} \geq 70$ letters versus those with $<25$ letters, mean VA variation at 5 years was -12.2 versus +8.1 letters, but mean final VA was 65.1 versus 24.5 letters, respectively. Patients submitted to cataract surgery during follow-up had a similar VA variance in comparison with the remaining study group.

Immediately after the beginning of anti-VEGF treatment, there was a rapid increase in the proportion of patients without IRF and SRF (to a peak value of 61\%) and decrease in mean CMT (maximum decrease of $114.0 \mu \mathrm{m}$ ) (Table 2). At the end of follow-up, the proportion of patients with dry retinas was $56 \%$, and mean CMT remained substantially inferior to baseline $(-96.6 \mu \mathrm{m})$.

\section{Discussion}

In this retrospective analysis of long-term outcomes of nAMD treatment with anti-VEGF agents at a tertiary center in Portugal, we obtained some encouraging results. After 5 years of follow-up, initial mean VA was maintained, the great majority of patients avoided moderate vision loss, and the proportion with VA of at least 20/40 almost doubled. These results were achieved through a personalized treatment regimen with fewer than monthly injections and visits.

Other authors have previously published retrospective analyses of nAMD treatment with anti-VEGF agents in clinical practice, on a PRN basis. ${ }^{9-12}$ In accordance with our results, these studies generally show an initial improvement in VA in response to treatment, which is then gradually lost over time, resulting in a final VA similar or slightly inferior to baseline. Single-center studies performed in Denmark ${ }^{9}$ and in Australia ${ }^{10}$ reported a significant increase in VA at the end of the first year, but no significant changes relative to baseline at the end of the fourth year, ${ }^{9,10}$ and a small but significant decrease at the end of the fifth year. ${ }^{10}$ Likewise, in a multicenter 3-year study conducted in the 
$\mathrm{UK}^{11}$ and a multicountry 2-year study, ${ }^{12}$ there was a gain of approximately two letters at the end of the first year, but this was not maintained over follow-up. In agreement with our results, the proportion of patients who avoided moderate vision loss was $90 \%$ at year 1 in the UK study ${ }^{11}$ and $80 \%$ at year 5 in the Australian one; ${ }^{10}$ in addition to this, the UK study ${ }^{11}$ also reported a twofold increase in the proportion of patients with VA $\geq 20 / 40$ at the end of the first year, which remained relatively stable thereafter. Globally, in the previously mentioned studies, ${ }^{9-12}$ the mean number of injections varied between 5.0 and 7.5 in the first year, 2.2 and 5.8 in the second year, and 3.7 and 6.4 in the third year, which is also in line with our results.

On the other hand, clinical practice results are inferior to those obtained in the pivotal clinical trials. In comparison to the ANCHOR and MARINA trials,,${ }^{1-3}$ in which participants were treated with monthly ranibizumab, mean VA change, proportion of patients gaining $\geq 15$ letters, and proportion of patients with VA $\geq 20 / 40$ were all considerably lower in our study at 1 and 2 years of follow-up. Our outcomes were also inferior to the ones obtained in the CATT study, even in the group of patients treated with bevacizumab PRN, who received on average 7.7 injections in the first year and 14.1 injections in total during 2 years. ${ }^{7,8}$ This might be partly explained by the lower number of injections in clinical practice. Additionally, it is not surprising that clinical trial results do not completely translate into clinical practice, as the population analyzed in both settings is quite different. These differences are apparent when comparing the baseline characteristics of patients included in our study and in the pivotal clinical trials: mean VA and proportion of patients with $V A \geq 20 / 40$ were in general considerably lower in our study.

However, in a retrospective analysis of clinical practice results, Peden et al recently reported that using fixed-interval dosing every 4-8 weeks, with an average number of injections of 10.5/year, a positive variation of $>10$ letters could be achieved even after 7 years of follow-up, with more than one third of patients presenting VA $\geq 20 / 40$ from 5 to 7 years. ${ }^{13}$ Interestingly, the baseline characteristics of the study group were similar to ours (mean VA of 45.6 letters and $10 \%$ of patients with $\mathrm{VA} \geq 20 / 40$ ), which suggests that the superior visual outcomes were attributable to differences in the treatment regimen.

Our study also confirmed that baseline VA greatly influences VA variation in response to treatment and the absolute final VA, as has been previously demonstrated. ${ }^{10,11,13}$ Patients with higher baseline VA tend to gain fewer letters or to lose more letters than those with lower baseline VA, but they maintain a higher absolute VA at the end of follow-up. The more limited potential of patients with higher baseline VA to gain vision (and conversely, the greater potential to lose vision) has been termed the "ceiling" effect, while the more limited potential of patients with lower baseline VA to lose vision has been termed the "floor" effect. ${ }^{11}$

Our study has several strengths but also some limitations. Considering that it was a single-center study of patients over 50 years of age (many of whom were elderly) treated in routine clinical practice, the number of patients included was reasonably large and the proportion of losses to follow-up reasonably low. Furthermore, we published results concerning a long follow-up period of 5 years. On the other hand, because patterns of treatment at our center varied during the follow-up period, different anti-VEGF agents and treatment regimens were analyzed simultaneously. In addition to this, not all patients were treatment-naïve at the time they initiated anti-VEGF therapy, but $18 \%$ had previously received PDT.

As the time elapsed since the introduction of anti-VEGF agents increases, it is important to determine the longterm outcomes that are being achieved in clinical practice throughout the world. While clinical practice results are, not surprisingly, inferior to those obtained in clinical trials, they are nevertheless encouraging. Anti-VEGF therapy, even when delivered through a personalized treatment regimen, with fewer than monthly injections and visits, can arrest the natural history of nAMD of rapid and progressive vision loss, and lead to long-term stabilization of VA in the great majority of patients. Baseline VA is of the utmost importance in predicting long-term VA with treatment, which underlines the need for early detection.

\section{Disclosure}

$\mathrm{AC}$ has participated in advisory boards for Alcon, Bayer, Novartis, and Alimera Sciences. MF has received travel grants from Bayer and Novartis. The other authors report no conflicts of interest in this work.

\section{References}

1. Brown DM, Kaiser PK, Michels M, et al. Ranibizumab versus verteporfin for neovascular age-related macular degeneration. $N$ Engl J Med. 2006;355(14):1432-1444.

2. Brown DM, Michels M, Kaiser PK, Heier JS, Sy JP, Ianchulev T. Ranibizumab versus verteporfin photodynamic therapy for neovascular age-related macular degeneration: two-year results of the ANCHOR study. Ophthalmology. 2009;116(1):57-65.e5.

3. Rosenfeld PJ, Brown DM, Heier JS, et al. Ranibizumab for neovascular age-related macular degeneration. $N$ Engl J Med. 2006;355(14): 1419-1431.

4. Tufail A, Patel PJ, Egan C, et al. Bevacizumab for neovascular age related macular degeneration (ABC trial): multicentre randomised double masked study. BMJ. 2010;340:c2459. 
5. Lalwani GA, Rosenfeld PJ, Fung AE, et al. A variable-dosing regimen with intravitreal ranibizumab for neovascular age-related macular degeneration: year 2 of the PrONTO study. Am J Ophthalmol. 2009; 148(1):43-58.e1.

6. Gupta OP, Shienbaum G, Patel AH, Fecarotta C, Kaiser RS, Regillo CD. A treat and extend regimen using ranibizumab for neovascular age-related macular degeneration clinical and economic impact. Ophthalmology. 2010;117(11):2134-2140.

7. CATT Research Group, Martin DF, Maguire MG, et al. Ranibizumab and bevacizumab for neovascular age-related macular degeneration. N Engl J Med. 2011;364(20):1897-1908.

8. Comparison of Age-Related Macular Degeneration Treatments Trials (CATT) Research Group, Martin DF, Maguire MG, et al. Ranibizumab and bevacizumab for treatment of neovascular age-related macular degeneration: two-year results. Ophthalmology. 2012;119(7):1388-1398.

9. Rasmussen A, Bloch SB, Fuchs J, et al. A 4-year longitudinal study of 555 patients treated with ranibizumab for neovascular age-related macular degeneration. Ophthalmology. 2013;120(12):2630-2636.
10. Zhu M, Chew JK, Broadhead GK, et al. Intravitreal ranibizumab for neovascular age-related macular degeneration in clinical practice: fiveyear treatment outcomes. Graefes Arch Clin Exp Ophthalmol. 2015; 253(8):1217-1225.

11. Writing Committee for the UK Age-Related Macular Degeneration EMR Users Group. The Neovascular Age-Related Macular Degeneration Database: multicenter study of 92976 ranibizumab injections. Report 1 - visual acuity. Ophthalmology. 2014;121(5):1092-1101.

12. Holz FG, Tadayoni R, Beatty S, et al. Multi-country real-life experience of anti-vascular endothelial growth factor therapy for wet age-related macular degeneration. Br J Ophthalmol. 2015;99(2):220-226.

13. Peden MC, Suñer IJ, Hammer ME, Grizzard WS. Long-term outcomes in eyes receiving fixed-interval dosing of anti-vascular endothelial growth factor agents for wet age-related macular degeneration. Ophthalmology. 2015;122(4):803-808.
Clinical Ophthalmology

\section{Publish your work in this journal}

Clinical Ophthalmology is an international, peer-reviewed journal covering all subspecialties within ophthalmology. Key topics include: Optometry; Visual science; Pharmacology and drug therapy in eye diseases; Basic Sciences; Primary and Secondary eye care; Patient Safety and Quality of Care Improvements. This journal is indexed on

\section{Dovepress}

PubMed Central and CAS, and is the official journal of The Society of Clinical Ophthalmology (SCO). The manuscript management system is completely online and includes a very quick and fair peer-review system, which is all easy to use. Visit http://www.dovepress.com/ testimonials.php to read real quotes from published authors. 